\title{
Pauses During Autobiographical Discourse Reflect Episodic Memory Processes in Early Alzheimer's Disease
}

\author{
Aurélie Pistono ${ }^{\mathrm{a}, \mathrm{b}, \mathrm{c}, *}$, Mélanie Jucla ${ }^{\mathrm{c}}$, Emmanuel J. Barbeau ${ }^{\mathrm{d}}$, Laure Saint-Aubert ${ }^{\mathrm{e}}$, Béatrice Lemesle ${ }^{\mathrm{f}}$, \\ Benjamin Calvet $^{\mathrm{g}}$, Barbara Köpke ${ }^{\mathrm{c}}$, Michèle Puel ${ }^{\mathrm{a}, \mathrm{b}, \mathrm{f}}$ and Jérémie Pariente ${ }^{\mathrm{a}, \mathrm{b}, \mathrm{f}}$ \\ a "Brain Imaging and Neurological Disabilities" joint research unit (UMR 825), INSERM, Toulouse University \\ Hospital, Toulouse, France \\ b “Brain Imaging and Neurological Disabilities” joint research unit (UMR 825), University of Toulouse III - Paul \\ Sabatier, Toulouse University Hospital, Toulouse, France \\ ${ }^{\mathrm{c}}$ Octogone-Lordat interdisciplinary research unit (EA 4156), University of Toulouse II - Jean Jaurès, Toulouse, \\ France \\ ${ }^{\mathrm{d}}$ Centre for Brain Research and Cognition (CerCo), CNRS - University of Toulouse III - Paul Sabatier, Toulouse, \\ France \\ ${ }^{\mathrm{e}}$ Department of Neurobiology, Care Sciences and Society, Center for Alzheimer Research, Division of Translational \\ Alzheimer Neurobiology, Karolinska Institutet, Novum, Stockholm, Sweden \\ ${ }^{\mathrm{f}}$ Neurology Department, Neuroscience Centre, Toulouse University Hospital, Toulouse, France \\ $\mathrm{g}_{\text {Adult and elder psychiatry Department, Limoges Hospital, Limoges, France }}$
}

Accepted 30 October 2015

\begin{abstract}
There is a large body of research on discourse production in Alzheimer's disease (AD). Some studies have focused on pause production, revealing that patients make extensive use of pauses during speech. This has been attributed to lexical retrieval difficulties, but pausing may also reflect other forms of cognitive impairment as it increases with cognitive load. The aim of the present study was to analyze autobiographical discourse impairment in AD from a broad perspective, looking at pausing behavior (frequency, duration, and location). Our first objective was to characterize discourse changes in mild cognitive impairment (MCI) due to AD. Our second objective was to determine the cognitive and neuroanatomical correlates of these changes. Fifteen patients with MCI due to AD and 15 matched cognitively normal controls underwent an ecological episodic memory task, a full neuropsychological assessment, and a 3D T1-weighted MRI scans. Autobiographical discourse collected from the ecological episodic memory task was recorded, transcribed, and analyzed, focusing on pausing. Intergroup comparisons showed that although patients did not produce more pauses than controls overall, they did make more between-utterance pauses. The number of these specific pauses was positively correlated with patients' episodic memory performance. Furthermore, neuroimaging analysis showed that, in the patient group, their use was negatively correlated with frontopolar area (BA 10) grey matter density. This region may therefore play an important role in the planning of autobiographical discourse production. These findings demonstrate that pauses in early AD may reflect a compensatory mechanism for improving mental time travel and memory retrieval.
\end{abstract}

Keywords: Episodic memory, language, mild cognitive impairment, natural language processing, neuroimaging

\footnotetext{
*Correspondence to: Aurélie Pistono, INSERM U825, Pavillon Baudot CHU Purpan, Place du Dr Baylac, 31059 Toulouse Cedex, France. Tel.: +33 5627461 88; E-mail: aurelie.pistono@inserm.fr.
}

\section{INTRODUCTION}

Although episodic memory impairment is often observed in Alzheimer's disease (AD), other forms 
of cognitive impairment may also be present, even in the early stages of the disease $[1,2]$. Language difficulty is one of the deficits that are frequently reported in patients. Research has shown that lexical-semantic deficits can occur in the very earliest stage of AD. These deficits have been observed in fluency [3], naming $[4,5]$, and semantic tasks $[5,6]$. More and more studies have been focusing on discourse production in $\mathrm{AD}$, with a view to assessing the functional use of language and cognition. In the present study, we sought to examine both memory and language impairment, through patients' autobiographical discourse.

Studies analyzing discourse in AD have shown that standardized tasks cannot capture the full extent of patients' lexical-semantic impairment. Some of these studies used description tasks, such as the Cookie Theft picture [7], which highlighted a reduction in semantic content $[8,9]$, a decrease in syntactic complexity [8], and an increase in word-finding difficulty, sometimes reflected in pausing [9]. Others used topic-directed interviews, which revealed decreased coherence [10, 11] and, in a few cases, pragmatic impairment [12]. Finally, some authors focused on autobiographical discourse, asking patients to talk about important events in their lives. Gayraud et al. [13], for instance, observed that patients with $\mathrm{AD}$ used words with a higher lexical frequency, made more pauses, and had more difficulty finding words and less efficient speech. Hoffmann et al. [14] also found that speech efficiency gradually decreased as the disease progressed, owing to greater hesitation during speech. For their part, Singh et al. [15] reported that patients with $\mathrm{AD}$ produced longer pauses than healthy participants. In other words, patients seemed to make a different use of pauses during autobiographical discourse, which the authors attributed to lexical retrieval difficulties. Other authors have stressed the point that discourse production involves other cognitive abilities besides lexical-semantic ones, including memory [16] and executive functions [17]. It is therefore possible that pauses observed during discourse reflect not only lexical retrieval difficulties, but also other cognitive processes.

Pauses are composite events. They can be divided into two major types: silent pauses, defined as "the perception of a silent portion in the speech signal" [18] and filled pauses, which "mark a hesitation on the part of the speaker" [19]. The number, type, and duration of pauses during discourse are governed by physiological constraints [18], but can also reflect cognitive processes. Pauses may indicate lexical decision-making. For example, when participants are asked to guess each successive word in an utterance, less predictable words are preceded by longer pauses [20]. They also reflect cognitive load, and increase when the talking point is unfamiliar [21] or more abstract [22]. Apart from their type, pauses can also be distinguished according to their location in the discourse. In Goldman-Eisler's typology, pauses at natural punctuation points are defined as grammatical pauses. Outside these grammatical junctures, they are labeled as non-grammatical [20]. Some authors have shown that pausing is most likely to occur at the beginning of an utterance and before longer utterances, where the cognitive load is higher (for a review, see [19]). These results suggest that grammatical pauses are more due to cognitive planning than non-grammatical ones. Examining articulatory characteristics at and around pauses, Ramanarayanan et al. [23] showed that nongrammatical pauses are unplanned during discourse, whereas grammatical ones belong to a higher cognitive plane.

Studies analyzing pauses in AD [13-15, 24] have been characterized by considerable methodological variability, in terms of the types of pauses that are analyzed (silent, filled, or both), the pause threshold (ranging from $200 \mathrm{~ms}$ to $2 \mathrm{~s}$ ), the population under scrutiny (ranging from mild cognitive impairment (MCI) to the most advanced stage), and the tasks that are used, which include autobiographical discourse [13], story re-telling [24], and interviews [15]. Moreover, with one notable exception [13], they have neverfocused on the location of the pauses. In the present study, we set out to specifically analyze the pattern of pause use.

Another relevant way of considering patients' difficulties is to analyze discourse production together with concurrent cognitive and anatomical changes. As far as we know, this kind of analysis has already been undertaken in several neurological disorders (frontotemporal lobar degeneration [25], Lewy body spectrum disorders [26], primary progressive aphasia [27]), but not in AD. Authors who have done this have found that fluency (speech rate and between-utterance pauses) is correlated with the frontopolar area (Brodmann area (BA) 10). This region plays a critical role in higherorder cognitive functions, including memory retrieval [28], prospective memory [29], multitasking [30], reasoning [31], and theory of mind [30]. Considering all these different results together, Burgess et al. [32] came up with a gateway hypothesis for BA 10, postulating that this area supports mechanisms involved in switching attention between external representations (i.e., cognition provoked by or oriented toward an external stimulus) and self-generated internal representations (i.e., stimulus-independent thoughts). This 
area therefore seems crucial for autobiographical discourse production.

In the present study, we set out to analyze pauses during the autobiographical discourse of patients with MCI due to AD and cognitively normal controls. We adopted a new procedure, whereby episodic memory is probed in a situation as close as possible to real life, all the while being controlled (similar to protocols already published [33, 34]), in order to achieve a suitable approximation of the real-life discourse impairment. This procedure was based on real-life mini-events. We investigated the production and location of pauses during this specific type of discourse, and also conducted full neuropsychological assessments and structural MRI scans. We predicted that patients would produce more pauses than controls during the autobiographical narratives, and that between-utterance pauses would be related to memory retrieval processes rather than to lexical retrieval. We also thought that BA 10 might be involved in switching attention between the events that participants had experienced and the current recall situation, and that between-utterance pauses might reflect this switching.

\section{MATERIALS AND METHODS}

\section{Participants}

All participants gave their informed consent. This study was approved by the local ethics committee (Comité de Protection des Personnes Sud-Ouest et Outre-Mer I) and the French Agency for the Safety and Security of Medical Devices (Agence Française de Sécurité Sanitaire des Produits de Santé, A90605-58).

We recruited 15 patients aged over 65 years with a diagnosis of MCI due to AD [1, 35]. They all came from the outpatient memory clinic of the Neurology Department of Toulouse University Hospital (France). A total of 15 matched cognitively normal participants were recruited, either among the patients' relatives or via posters in public places.

\section{Pre-inclusion assessment}

Patients were invited to enroll in the study if they presented with a memory complaint that had lasted at least 6 months, had no concomitant history of neurological or psychiatric disease, and were not affected by any clinically significant pathology that might explain their memory complaint. Patients then underwent the following:
Pre-inclusion neuropsychological assessment: Autonomy in daily life was assessed using the Clinical Dementia Rating (CDR [36]) scale. Anterograde verbal memory was assessed using the Free and Cued Selective Reminding Test (FCSRT [37]).

Brain MRI: This was performed for all participants, using a Philips 3T Intera Achieva (Philips, Best, The Netherlands). 3D T1- and T2-weighted sequences were obtained. The $\mathrm{T} 2$-weighted images were examined by a neuroradiologist with extensive experience and blind to the clinical data, who rated them for white-matter changes using on the Fazekas and Schmitt (F\&S) scale [38].

Amyloid assessment: This was performed using either cerebrospinal fluid (CSF) analysis and/or amyloid positron emission tomography (PET) imaging.

CSF samples were obtained by lumbar puncture. CSF biomarker levels of total tau (T-Tau), phosphotau (P-Tau), $A \beta_{42}$, and $A \beta_{40}$ were measured using an ELISA method (Innogenetics, Gent, Belgium). We calculated the Innotest Amyloid Tau Index (IATI). P-Tau $\geq 60 \mathrm{pg} / \mathrm{mL}$ and IATI $\leq 0.8$ were deemed to be suggestive of $\mathrm{AD}$ [39]. In the case of an ambiguous profile (P-Tau $<60 \mathrm{pg} / \mathrm{mL}$ or IATI $>0.8$ ), we calculated the $\mathrm{A} \beta_{42} / \mathrm{A} \beta_{40}$ ratio, and a score $<0.045$ was taken to be compatible with a diagnosis of AD [40].

Florbetapir (AV-45) PET scan: Cerebral emission scan acquisitions began $50 \mathrm{~min}$ after an injection of 3.7 MBq/kg of AV-45, and lasted $10 \mathrm{~min}$. Images were visually analyzed by two trained nuclear medicine, who rated each image as amyloid positive or negative [41, 42].

Healthy controls underwent exactly the same neuropsychological assessments and MRI scans as the patients.

\section{Inclusion criteria}

Following the pre-inclusion assessment, patients were included in the present study if they met the following criteria for MCI due to $\mathrm{AD}[1,35]$ : $\mathrm{CDR} \leq 0.5$, sum of the three free recalls $\leq 17 / 48$ and/or sum of the three free and cued recalls $\leq 40 / 48$ in the FCSRT [43], and evidence of amyloid pathology in CSF [39] and/or positive AV-45 PET imaging [41, 42]. Patients with significant white-matter T2 hyperintensities (F\&S score $>2$ ) or with clinically significant lesions were excluded.

Cognitively normal individuals were included if they had no memory complaint, no history of 
neurological or psychiatric disease, and no first-degree relatives with AD. They were excluded if they had significant white-matter hyperintensities on their T2weighted MR images (F\&S score $>2$ ) or if either the pre- or post-inclusion neuropsychological assessment revealed cognitive impairment (test scores $>2$ standard deviations ( $S D$ s) below the norm).

\section{Post-inclusion assessment}

\section{Standard neuropsychological assessment}

All participants underwent a comprehensive neuropsychological assessment. Visual memory was tested with the immediate and delayed recall conditions of the Rey-Osterrieth complex figure [44] and the DMS48 visual recognition memory task [45]. Semantic memory was explored with the Information subtest of the Wechsler Adult Intelligence Scale (WAIS-III) [46] and the TOP12 test assessing semantic memory about the lives of 12 celebrities from their faces [47]. Working memory was probed with the WAIS-III Digit Span subtest, and attention with the Symbol Digit subtest of the WAIS-III. Executive functions were assessed with the Trail Making Test B [48] and the Frontal Assessment Battery [49]. Language was assessed with the phonological (letter $p$ ) and categorical (animals) fluency tests [50] and the picture-naming task (DO80) [51], while other tests probed visuospatial abilities (copy of the Rey-Osterrieth complex figure) and visuoperceptive abilities (Benton Facial Recognition Test [52]). Anxiety and depression were also measured, using the State-Anxiety Inventory (Y-A form; [53]) and the Beck Depression Inventory [54].

\section{Ecological memory assessment}

Epitoul is an innovative and ecological test of anterograde autobiographical episodic memory. Usual neuropsychological assessment takes place in the same room and within a relatively short period of time, which limits rich multi-modal context that usually characterizes events stored in episodic memory. Overall, personal involvement of subjects during neuropsychological assessment is minimal since the subject is not a direct actor of what is going on. Interestingly, the use of other procedures based on real-world $[33,55]$ tasks appeared relevant to investigate memory impairment and even more sensitive than laboratory setting to detect subtle deficits [34]. Likewise, Epitoul is based on a "real life" experience in which subjects are living 8 stereotyped mini-events within the facilities of the hospital with an implicit encoding. The 8 mini-events are identified and considered as strik- ing, contextualized, and checked, always taking in the same order and in the same places (Supplementary Table 1). The learning of this test is incidental. He knows only that he participates in a neuropsychological investigation, but that this one will be made more later during the day. The whole session lasted about 25 minutes.

After a 20-minute interval, participants were asked to recall the mini-events they had experienced: "I would like you to chronologically recall everything we did between the moment we met and the moment we returned to the office. You must try to recall this episode for me in the greatest possible detail, as though you were reliving it, in the order of the real-life events: what we did, what we saw, where we went, the circumstances and any events that occurred, what you felt or thought. I'm listening to you."

When they had completed their oral descriptions, the experimenter asked them to look back over the itinerary and try to think of more details. Further to the free reminder, they were asked open questions about each of the eight real-life events: "Very well. Do you have anything to add? I' $m$ going to give you some information that will help you remember more details about this event".

The experimenter only asked questions about elements that had not been supplied by the participant during the free recall. Other questions are evaluated with the maximum of points.

Recall responses were taped with a digital recorder and assessed by two experimenters. Each mini-event was rated on a 4-point scale for both the free and the cued recall. The maximum score for each type of recall was therefore 32. (The scoring grid is available in Supplementary Table 2.)

All assessments and imaging examinations, from pre-inclusion to post-inclusion, were performed within three months.

\section{Autobiographical discourse analysis}

The spontaneous discourses produced during the free recall component of the Epitoul test formed the core of the present study. We focused our analysis on pauses. Discourse analyses were limited to no more than three prompts from the experimenter.

\section{Transcribing and coding}

Participants' oral productions were manually and orthographically transcribed with the Child Language Data Exchange System (CHILDES; MacWhinney, 2011), using the embedded Computerized Language Analysis (CLAN) software program and its 
CHAT transcription norms. This system automatically extracts quantitative data (i.e., number of each type of pauses). For the purpose of the analysis, utterances were annotated while listening to the recording (i.e., falling intonations for declarative utterances and rising ones for questions).

\section{Pause analysis}

Pause type and length were manually tagged with Audacity software (http://audacity.sourceforge.net/), using a 250-ms threshold [20]. This cut-off point of $250 \mathrm{~ms}$ was chosen to differentiate articulatory pauses from hesitation ones [20]. We included both silent and filled pauses in our analysis (in the following examples, pauses are indicated by the sign //). Regarding the location of these pauses, we began by distinguishing between-utterance pauses (e.g., "you went to the other side. // you bought the newspaper. // you talked about chocolate") from within-utterance pauses (e.g., "we walked // a short time"). We were particularly interested in this distinction, as the beginning of an utterance is assumed to be the most cognitively demanding [19, 20], and between-utterance pauses therefore presumably reflect planning for the upcoming thought more than other pauses do. The case has already been made for drawing this distinction when analyzing the narratives of patients with AD [15].

For within-utterance pauses, we followed GoldmanEisler's typology. We annotated grammatical pauses, that is, those occurring at natural punctuation junctures (e.g., "in the first building // or another one"). We also annotated non-grammatical pauses, that is, those produced outside these grammatical junctures, in the middle or toward the end of a phrase (e.g., "we bought a // newspaper"), between repeated words and phrases (e.g., "then // then we went outside"), in the middle of a verbal compound (e.g., "I have // taken"), or in a false start or reconsideration (e.g., "we walked to // you did it on purpose?").

To sum up, we annotated between-utterance pauses and within-utterance pauses (both grammatical and non-grammatical), as shown in the following example taken from a patient's free recall (parentheses indicate pause type and length in seconds):

"We went to the secretary's office. (betweenutterance: 1.710) there was a (within-utterance non-grammatical: 0.566) nobody there. (betweenutterance: 0.487) then we crossed the corridor. (between-utterance: 1.066) we went into a room just the two of us (within-utterance grammatical: 0.355) and you hmm (within-utterance non-grammatical: 0.447) asked me today's date (within-utterance grammatical: 0.682) I remember that."

\section{Variables}

The following variables were used to analyze the discourse of the patients and cognitively normal controls:

- Discourse organization: total number of words in the narrative, total number and mean length of pauses, total speech duration, speech rate and pause rate per 100 words;

- Pause use: between-utterance, within-utterance grammatical and within-utterance non-grammatical pause rates per 100 words; percentages of between-utterance pauses, within-utterance grammatical pauses and within-utterance nongrammatical pauses.

\section{Statistical analysis}

\section{Behavioral data}

All the statistical analyses were performed using the Statistica software package, Version 8 (StatSoft, 2007).

Intergroup comparisons: Because of the small sample sizes, we used a nonparametric Mann-Whitney $U$ test to study differences between groups. $P$ values were adjusted for multiple comparisons according to Holm's stepdown procedure (Holm, 1979). The size effect was assessed using Cohen's $d$.

Correlations between the EPITOUL ecological task and standardized memory tasks: Spearman's rank correlation test was used to assess the strength of correlations in the patient group between the Epitoul cued recall scores and the sum of the three free and cued recalls on the FCSRT, the Rey figure and the DMS48 Set 2 .

Correlations between pausing and cognitive abilities: Spearman's rank correlation test was used to assess the association between behavioral performance and neuropsychological performance in the shape of anterograde episodic memory (Epitoul cued recall; sum of the three free and cued recalls on the FCSRT) and lexical-semantic aspects of language (picture-naming and semantic fluency tasks). Correlations were calculated separately for each group. As all correlations were motivated by a priori hypotheses, corrections for multiple comparisons were not performed. 


\section{Neuroimaging data}

All the following neuroimaging analyses were performed using Statistical Parametric Mapping software Version 8 (SPM8; Wellcome Trust Centre for Neuroimaging, London, UK). 3D T1 images were first segmented for each participant, using a voxel-based morphometry (VBM) method to isolate the greymatter partition, and normalized into the MNI standard space. The resulting modulated normalized greymatter maps were then smoothed $(8 \times 8 \times 8 \mathrm{~mm})$ and pooled by group for statistical analysis.

Intergroup comparison: Cortical grey-matter density differences between the two groups were assessed using voxel-based analysis (threshold for significance: $p=0.001$, uncorrected; cluster $=20$ voxels ).

Correlation analyses: Correlations between greymatter density and percentages of between-utterance pauses and non-grammatical pauses, were assessed in each group using multiple regression (threshold for significance: $p=0.001$, uncorrected; cluster $=20$ voxels) for specific regions of interest (ROIs), in accordance with our hypotheses. The first ROI was defined using the Brodmann atlas: BA 10, corresponding to the bilateral frontopolar areas. The second ROI (right and left hippocampi) was extracted using automatic regional labeling (anatomical automatic labeling, AAL [56]).

\section{RESULTS}

\section{Pre-inclusion assessment}

Fifteen patients with MCI due to $\mathrm{AD}$ and 15 cognitively normal individuals were included in the study. Demographic data and performances on the preinclusion neuropsychological assessment are detailed in Table 1. Patients and controls were matched for age and level of education. Patients had significantly lower FCSRT, MMSE, and CDR scores. CSF samples were available for 13 of the 15 patients. Amyloid pathology was found in all of them. For the two remaining patients, the AV-45 PET scan was rated as positive for amyloid retention. None of the patients or cognitively normal controls had an F\&S score $>2$.

\section{Neuropsychological assessment}

Patients exhibited significant anterograde declarative memory impairments on all tests. Their performances were also impaired on both free and cued recall in the Epitoul test. Patients presented minor language impairments (on naming and semantic fluency). Their processing speed and executive performance were also lower than controls. No deficits were found in the other cognitive domains. Patients were neither depressed nor anxious (Table 2).

\section{Discourse analysis}

\section{Discourse organization}

Patients produced fewer words during recall than controls, but their total speech duration did not differ significantly. Patients also produced longer pauses on average, but did not pause more often than controls, as pause rates per 100 words did not differ significantly. All the results are shown in Table 3.

\section{Pause use}

Concerning the rate per 100 words of each type of pause, we found that patients did not produce more within-utterance pauses than controls. This applied to both grammatical within-utterance pauses (patients = $16.36 \pm 6.11$, controls $=14.63 \pm 5.74 ; p=0.51$ ) and non-grammatical within-utterance pauses (patients = $4.05 \pm 2.23$; controls $=8.45 \pm 5.66 ; p=0.54$ ). However, their between-utterance pause rate per 100

Table 1

Clinical assessment

\begin{tabular}{|c|c|c|c|}
\hline & Cognitively normal participants $(n=15)$ & Patients $(n=15)$ & $p$ value \\
\hline Gender & $4 \mathrm{M}-11 \mathrm{~F}$ & $9 \mathrm{M}-6 \mathrm{~F}$ & 0.07 \\
\hline Age & $68.5 \pm 4.3$ & $71.5 \pm 6.1$ & 0.053 \\
\hline Level of education (in years) & $13.3 \pm 3.7$ & $10.9 \pm 2.6$ & 0.09 \\
\hline CDR scale & $0.0 \pm 0.0$ & $0.5 \pm 0.0$ & $<0.001$ \\
\hline MMSE (/30) & $28.6 \pm 0.7$ & $24.6 \pm 2.9$ & $<0.0001$ \\
\hline FCSRT: Sum of free recalls (/48) & $32.8 \pm 5.3$ & $10.8 \pm 5.6$ & $<0.0001$ \\
\hline FCSRT: Sum of free \& cued recalls (/48) & $46.9 \pm 1.6$ & $28.8 \pm 12$ & $<0.0001$ \\
\hline FCSRT: delayed total recall (/16) & $15.9 \pm 0.4$ & $11 \pm 4.1$ & $<0.0001$ \\
\hline
\end{tabular}

CDR scale, Clinical Dementia Rating scale; MMSE, Mini-Mental State Examination; FCSRT, Free and Cued Selective Reminding Test. Values shown are mean $\pm S D$. Statistically significant results are shown in bold. 
Table 2

Neuropsychological assessment

\begin{tabular}{|c|c|c|c|c|c|}
\hline Cognitive field & Test & $\begin{array}{c}\text { Cognitively } \\
\text { normal participants }\end{array}$ & Patients & $p$ value & $\begin{array}{l}\text { Cohen's } \\
d \text { values }\end{array}$ \\
\hline \multirow[t]{3}{*}{ Visual anterograde memory } & DMS 48 Set $1(/ 48)$ & $45.1 \pm 8.9$ & $41.3 \pm 4.8$ & $<0.0001$ & 0.53 \\
\hline & DMS 48 Set $2(/ 48)$ & $46.9 \pm 1.1$ & $40.9 \pm 5.1$ & $<0.0001$ & 1.62 \\
\hline & Rey complex figure recall (/36) & $18.7 \pm 5.8$ & $10 \pm 6.2$ & $<0.0001$ & 1.45 \\
\hline \multirow[t]{3}{*}{ Semantic memory } & WAIS-III Information subtest (/28) & $20.1 \pm 6.2$ & $13.8 \pm 5.5$ & 0.01 & 1.07 \\
\hline & TOP12 faces: overall score (/96) & $84.6 \pm 6.0$ & $74.8 \pm 6.7$ & $<0.01$ & 1.54 \\
\hline & TOP12 faces: naming score (/12) & $9.3 \pm 2.2$ & $5.2 \pm 3.4$ & $<0.01$ & 1.43 \\
\hline \multicolumn{6}{|c|}{ Ecological memory assessment } \\
\hline \multirow[t]{2}{*}{ Epitoul } & free recall (/32) & $27.4 \pm 3$ & $11.6 \pm 7.5$ & $<0.0001$ & 2.77 \\
\hline & cued recall (/32) & $27.1 \pm 2.5$ & $14.2 \pm 5.1$ & $<0.0001$ & 3.2 \\
\hline \multirow[t]{3}{*}{ Language } & DO80 (/80) & $79.7 \pm 0.8$ & $77.1 \pm 4.7$ & 0.02 & 0.77 \\
\hline & Phonological fluency (letter $p$ ) & $24.1 \pm 6.8$ & $20.9 \pm 8.3$ & 0.58 & 0.42 \\
\hline & Semantic fluency (animals) & $35.9 \pm 7.2$ & $21.8 \pm 6.9$ & $<0.0001$ & 2 \\
\hline Speed processing & Digit-Symbol test (/90) & $52.8 \pm 10.2$ & $34.1 \pm 12.6$ & $<0.01$ & 1.63 \\
\hline \multirow[t]{2}{*}{ Executive functions } & TMT B (time) & $86.5 \pm 22.3$ & $176.9 \pm 85$ & $<0.01$ & 1.45 \\
\hline & Frontal assessment battery (/18) & $17.1 \pm 1$ & $15.1 \pm 2.4$ & 0.04 & 1.09 \\
\hline Short-term memory & WAIS-III Forward digit span & $5.5 \pm 0.8$ & $5.6 \pm 1.3$ & 0.55 & 0.09 \\
\hline Working memory & WAIS-III Backward digit span & $4.9 \pm 1.1$ & $4.2 \pm 1.3$ & 0.24 & 0.58 \\
\hline Visuospatial abilities & Rey complex figure copy (/36) & $34.6 \pm 1.4$ & $33.1 \pm 3.5$ & 0.95 & 0.56 \\
\hline Visuo-perceptive abilities & Benton facial recognition (/58) & $48.1 \pm 3.5$ & $46.0 \pm 3.3$ & 0.47 & 0.62 \\
\hline Depression scale & Beck Depression Inventory & $17.1 \pm 1$ & $15.1 \pm 2.4$ & 0.70 & 0.14 \\
\hline Anxiety scale & Y-A & $30.2 \pm 7.1$ & $33.7 \pm 10.8$ & 0.59 & 0.38 \\
\hline
\end{tabular}

WAIS, Wechsler Adult Intelligence Scale; TMT, Trail Making Test. Values shown are mean $\pm S D$. Statistically significant results are shown in bold.

Table 3

Summary of results

\begin{tabular}{|c|c|c|c|c|}
\hline Variables & Cognitively normal participants & Patients & $p$ value & Cohen's $d$ values \\
\hline Mean total number of words & $590.6 \pm 266$ & $367.9 \pm 183$ & 0.04 & 0.98 \\
\hline Mean total speech duration (in s) & $219.7 \pm 110$ & $169.2 \pm 89$ & 0.23 & 0.5 \\
\hline Mean total number of pauses & $107.5 \pm 62$ & $74.4 \pm 45$ & 0.13 & 0.61 \\
\hline Mean pause length (in ms) ${ }^{1}$ & $699 \pm 218$ & $1215 \pm 594$ & 0.02 & 1.15 \\
\hline Speech rate (in words per $s)^{2}$ & $2.8 \pm 0.6$ & $2.3 \pm 0.77$ & 0.04 & 0.72 \\
\hline Pause rate per 100 words $^{3}$ & $18 \pm 7$ & $20.4 \pm 8$ & 0.37 & 0.33 \\
\hline Non-grammatical pause rate per 100 words & $3.4 \pm 1.7$ & $4.1 \pm 2.2$ & 0.54 & 0.36 \\
\hline Within-utterance pause rate per 100 words & $14.6 \pm 5.7$ & $16.4 \pm 6.1$ & 0.51 & 0.3 \\
\hline Between-utterance pause rate per 100 words & $5 \pm 2.2$ & $7.5 \pm 2.5$ & 0.04 & 1.06 \\
\hline Percentage of non-grammatical pauses & $19.5 \pm 8.6$ & $19.5 \pm 6.6$ & 0.74 & 0 \\
\hline Percentage of within-utterance pauses & $80.5 \pm 8.6$ & $80.5 \pm 6.6$ & 0.74 & 0 \\
\hline Percentage of between-utterance pauses & $29.1 \pm 10.4$ & $39.3 \pm 11.7$ & 0.04 & 0.92 \\
\hline
\end{tabular}

Values shown are mean $\pm S D$. Statistically significant results are shown in bold and are corrected for multiple comparisons. ${ }^{1}$ Mean pause length $=$ total pause duration/total number of pauses. ${ }^{2}$ Speech rate $=$ total number of words/total speech duration. ${ }^{3}$ Rate per 100 words $=$ total number of pauses considered / total number of words*100.

words was higher (patients $=7.49 \pm 2.5$, controls $=$ $5.04 \pm 2.17 ; p=0.04, d=1.06$, corrected results).

As shown in Fig. 1, results based on the percentage of each type of pause pointed to a similar use of pausing in each group, except for between-utterance pauses.

\section{Correlations with cognitive performance}

Ecological memory assessment: In the patient group, Epitoul cued recall was correlated with the three FCSRT free and cued recalls $(r=0.54, p=0.04)$, the Rey figure $(r=0.54, p=0.04)$, and the DMS48 Set 2 $(r=0.53, p=0.04)$.
Anterograde episodic memory: In the patient group, the between-utterance pause rate per 100 words was positively correlated with Epitoul cued recall $(r=0.55, p=0.03)$ and with the sum of the three FCSRT free and cued recalls $(r=0.58, p=0.02)$. Similarly, the percentage of between-utterance pauses was positively correlated with both Epitoul cued recall $(r=0.71, p=0.003$; Fig. 2$)$ and the sum of the three FCSRT free and cued recalls $(r=0.54, p=0.02)$. The non-grammatical within-utterance pause rate per 100 words was positively correlated with Epitoul cued recall $(r=0.54, p=0.04)$, as well as with the percentage of non-grammatical within-utterance pauses 


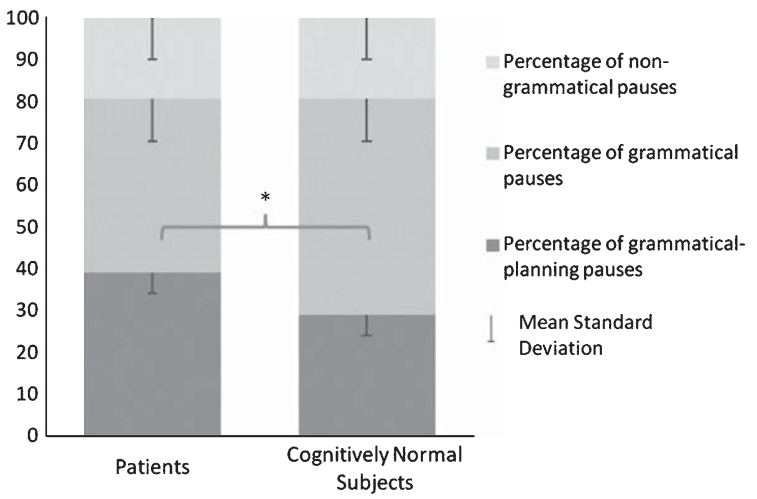

Fig. 1. Intergroup comparison on pause distribution. Significance threshold in Mann-Whitney test set at $p=0.05$.

( $r=0.73, p=0.002)$, but these pauses were not correlated with the sum of the three FCSRT free and cued recalls (non-grammatical within-utterance pause rate per 100 words: $r=0.1, p=0.72$; percentage of non-grammatical within-utterance pauses: $r=0.17$, $p=0.55)$.

In the cognitively normal group, the betweenutterance pause rate per 100 words was negatively correlated with Epitoul cued recall $(r=-0.72$, $p=0.002)$, but not with the sum of the three FCSRT free and cued recalls $(r=0.12, p=0.68)$. The percentage of between-utterance pauses also appeared to be negatively correlated with Epitoul, albeit to a lesser extent ( $r=-0.54, p=0.04$; Fig. 2), but not with the FCSRT $(r=-0.36, p=0.19)$. No correlations were found with the percentage of non-grammatical within-utterance pauses in this group.

Lexical-semantic performance: No correlations were observed in either group between the naming and semantic fluency tasks and the different types of pauses.

\section{Neuroimaging results}

\section{Intergroup comparison}

Compared with controls, patients had significant temporal atrophy, mainly located in the left anterior hippocampus and right posterior hippocampus, as well as frontal and parietal grey-matter loss (Supplementary Fig. 1).

\section{Correlation analyses}

In the patient group, we found a negative correlation between the percentage of between-utterance pauses and grey-matter density in BA $10(\mathrm{~T}=6.27 ; \mathrm{x}=10$, $y=68, z=12$ ) (Fig. 3). No correlations were found with the hippocampi. No correlation was found in the control group for either ROI.

\section{DISCUSSION}

In this study, we sought to gain a better understanding of aspects of autobiographical discourse impairment in $\mathrm{AD}$, adopting an approach that combined psycholinguistic measures with neuropsychological and neuroimaging data. We showed that, compared with cognitively normal controls, patients with $\mathrm{MCI}$ due to $\mathrm{AD}$ made greater use of betweenutterance pauses. Moreover, only in this group the number of these specific pauses was positively correlated with episodic memory performance. Finally, we showed a link between BA 10 atrophy and the production of between-utterance pauses.
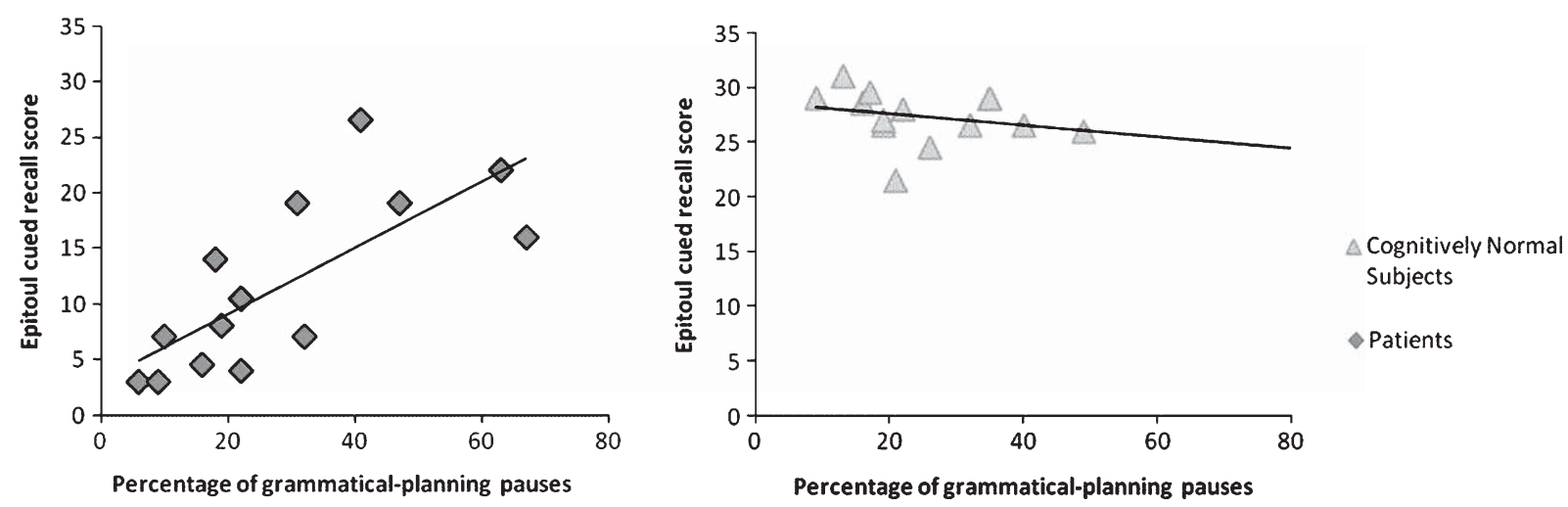

Fig. 2. Correlations between between-utterance pause production and memory performance on Epitoul cued recall subtest in the group with mild cognitive impairment due to Alzheimer's disease (left), and the cognitively normal group (right). 

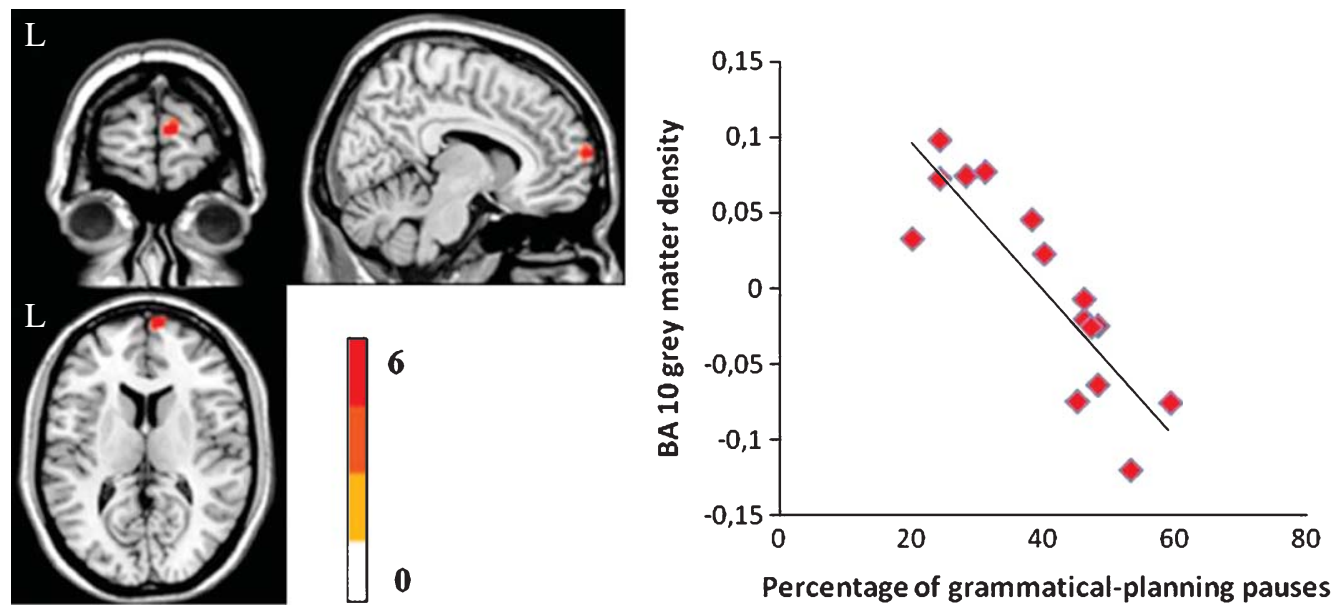

Fig. 3. Correlation between frontopolar grey-matter density (y-axis) and percentage of between-utterance pauses in patients' free recall (x-axis). Significance threshold set at $p=0.001$ (uncorrected).

\section{Pausing during autobiographical discourse in Alzheimer's disease}

Patients were less efficient than controls during autobiographical discourse production. Despite a comparable number of pauses, patients produced fewer words per minute because their pauses were longer. Contrary to the findings of previous studies [13], patients did not produce more non-grammatical withinutterance or grammatical within-utterance pauses than controls. Patients did, however, use more betweenutterance pauses than controls in their discourses, and these pauses represented a higher proportion of total pauses. The use of between-utterance pauses may reflect a greater need for recall and planning during autobiographical discourse. This hypothesis was mentioned by Singh et al. [15]. Those authors demonstrated that patients had lower speech rates because of longer pauses, and not because of more frequent ones. For the authors, planning difficulties was a possible explanation of these results. According to them, effort and planning are reflected more by long pauses than by frequent ones. They also suggested that pauses at the beginning of utterances needed to be investigated in greater detail, in order to focus on planning difficulties. Other authors have highlighted links between pauses and cognition: Hoffmann et al. [14] showed that speech and hesitation rates were negatively correlated with patients' global cognitive performance assessed by the MMSE scores. We cannot rule out possible lexical access impairment in the interpretation of these results.

Both non-grammatical within-utterance pauses and between-utterance pauses were positively correlated with patients' performances on Epitoul cued recall. We suggest that, in order to provide episodic details during their discourse, patients had to make non-grammatical, within-utterance pauses. By contrast, pausing between utterances may have been a compensatory strategy. Taking time between two utterances had a positive effect on patients' memory recall and discourse planning, leading to better memory performance. In the cognitively normal group, between-utterance pauses were negatively correlated with episodic memory performance. In other words, controls with higher rates of between-utterance pauses had lower memory scores. Healthy individuals are probably able to carry out mental travel and discourse planning without needing to pause.

In previous studies of autobiographical discourse, pausing was attributed to lexical-semantic deficits [13, 14]. In the present study pausing was not correlated with lexical-semantic processing in either group. Our results lead to several conclusions that differ from those reached in previous studies of speech processing in AD. While not denying the presence of an early lexical and semantic impairment, we highlight another link with cognition. We should, however, point out that these results may have been influenced by the high cognitive load of the task we administered as autobiographical recall is probably more difficult than standardized tasks. Access to the lexicon may also be more challenging for patients than lexical-semantic tasks we used during the neuropsychological assessment. Nonetheless, the fact that patients were slightly impaired on the naming task may minimize the expected correlation between naming and pauses produced during Epitoul recall. It 
would therefore be interesting to go further with more sensitive lexical-semantic tasks to test links between memory and lexical impairment.

\section{Neuroimaging data and autobiographical discourse}

Our neuroimaging analysis shed light on the relation between BA 10 grey matter density and betweenutterance pauses. Among patients, percentage of between-utterance pauses was negatively correlated with BA 10 grey-matter density: patients who produced more between-utterance pauses had greater atrophy in this region. We hypothesize that between-utterance pauses constitute a mechanism that compensates for deficits in memory access and discourse planning. This is consistent with the gateway hypothesis [32], as between-utterance pauses are thought to reflect a gateway between inner life (i.e., introspection, mental time travel, recall planning) and the outside world (i.e., current recall situation). According to this hypothesis, attention is continuously switched between internal and external processing when performing a task. However, as patients have greater atrophy than healthy individuals, this switching between their mental life and the outside world is still possible, but takes more effort. We hypothesize that one way for them to remedy this is to make pauses. We can assume that in the control group, the gateway between the previous mini-events and recall was established immediately, without any need for pausing.

More generally, frontopolar area is known to play an important role in human cognition: it is involved in different cognitive operations and supports a wide range of cognitive tasks. Despite increasing research, this region remains rather puzzling, and results are variable. To explain this variability, Burgess et al. [32] argued that BA 10 gateway is important during ill-structured situations. Ill-structured situations are situations where it is not obvious how to behave [57], which is the case of many communicative situations. Discourse processing can certainly be regarded as an ill-structured situation, as it requires topic, cognitive, and behavioral management that varies with the circumstances. However, frontopolar area functions have rarely been investigated by means of language tasks. Using structural imaging, Ash et al. [26] found that impaired speech fluency during storytelling was related to BA 10 atrophy in Lewy body spectrum disorder. Basso Moro et al. [58], meanwhile, using spoken narrative recall in healthy individuals, observed frontopolar activation during retrieval processes, which they attributed to the construction of the overall coherence that is crucial for story recall.

\section{Future directions}

Using autobiographical discourse has several clinical benefits. As indicated by Bliss et al. [59], it represents the most challenging type of narrative. It requires planning around a theme, but also reflects social skills and functional communication.

In the present study, we showed a correlation between pauses and memory performance in an autobiographical memory task. It would be useful to compare this task with a narrative discourse based on visual cues. This would be an interesting way of determining the influence of memory, planning and lexical retrieval during discourse production in patients with AD.

Moreover, narrative tasks are supposed to reflect everyday communication. Our results may open up new rehabilitation perspectives for patients with neurodegenerative disorders. If pausing improves memory processing and/or discourse planning, one way of enhancing patients' narrative performance would be to develop rehabilitation programs that encourage patients to pause and take the time to relive the event they are talking about.

\section{ACKNOWLEDGMENTS}

The authors thank the patients and control participants who took part in this study, as well as the promoter of this study, Toulouse University Hospital (CHU), and the clinical manager Delphine Vernet. Our gratitude goes to Nathalie Vayssière, Hélène Gros, Lucette Foltier and Jean-Pierre Désirat of the MRI technical platform (INSERM UMR825) for their invaluable assistance. Authors also thank Gaelle Vayssière for her help to Epitoul assessment. This study was supported by a grant from CHU Toulouse (local grant 2007), and a grant from the French National Research Agency (ANR).

Authors' disclosures available online (http://j-alz. com/manuscript-disclosures/15-0408r2).

\section{SUPPLEMENTARY MATERIAL}

The supplementary material is available in the electronic version of this article: http://dx.doi.org/10.3233/ JAD-150408. 


\section{REFERENCES}

[1] Dubois B, Feldman HH, Jacova C, Hampel H, Molinuevo JL, Blennow K, DeKosky ST, Gauthier S, Selkoe D, Bateman R, Cappa S, Crutch S, Engelborghs S, Frisoni GB, Fox NC, Galasko D, Habert M-O, Jicha GA, Nordberg A, Pasquier F, Rabinovici G, Robert P, Rowe C, Salloway S, Sarazin M, Epelbaum S, de Souza LC, Vellas B, Visser PJ, Schneider L, Stern Y, Scheltens P, Cummings JL (2014) Advancing research diagnostic criteria for Alzheimer's disease: The IWG-2 criteria. Lancet Neurol 13, 614-629.

[2] Berisha V, Wang S, LaCross A, Liss J (2015) Tracking discourse complexity preceding Alzheimer's disease diagnosis: A case study comparing the press conferences of presidents Ronald Reagan and George Herbert Walker Bush. $J$ Alzheimers Dis 45, 959-963.

[3] Nutter-Upham KE, Saykin AJ, Rabin LA, Roth HAW, Pare N, Flashman LA (2009) Verbal fluency performance in amnestic MCI and older adults with cognitive complaints. Arch Clin Neuropsychol 23, 229-241.

[4] Ahmed S, Arnold R, Thompson SA, Graham KS, Hodges JR (2008) Naming of objects, faces and buildings in mild cognitive impairment. Cortex 44, 746-752.

[5] Joubert S, Brambati SM, Ansado J, Barbeau EJ, Felician O, Didic M, Lacombe J, Goldstein R, Chayer C, Kergoat M$\mathrm{J}$ (2010) The cognitive and neural expression of semantic memory impairment in mild cognitive impairment and early Alzheimer's disease. Neuropsychologia 48, 978-988.

[6] Barbeau EJ, Didic M, Joubert S, Guedj E, Koric L, Felician O, Ranjeva J-P, Cozzone P, Ceccaldi M (2012) Extent and neural basis of semantic memory impairment in mild cognitive impairment. J Alzheimers Dis 28, 823-837.

[7] Goodglass H, Kaplan E (1984) The assessment of aphasia and related disorders By Harold Goodglass and Edith Kaplan, Philadelphia, Lea \& Febiger, 1983 illustrated, \$27.50 (package). Ann Neurol 16, 625.

[8] Ahmed S, Haigh AF, Jager CA, De, Garrard P (2013) Connected speech as a marker of disease progression in autopsy-proven Alzheimer's disease. Brain 10, 1-11.

[9] Forbes-McKay KE, Venneri A (2005) Detecting subtle spontaneous language decline in early Alzheimer's disease with a picture description task. Neurol Sci 26, 243-354.

[10] Brandao L, Lima TM, Parente MA, Pena-Casanova J (2013) Discourse coherence and its relation with cognition in Alzheimer's disease. Psicologia Pesquisa 7, 99-107.

[11] Dijkstra K, Bourgeois MS, Allen RS, Burgio LD (2004) Conversational coherence: Discourse analysis of older adults with and without dementia. $J$ Neurolinguistics 17, 263-283.

[12] Rousseaux M, Sève A, Vallet M, Pasquier F, MackowiakCordoliani MA (2010) An analysis of communication in conversation in patients with dementia. Neuropsychologia $\mathbf{4 8}$, 3884-3890.

[13] Gayraud F, Barkat-Defradas M, Lee H (2011) Syntactic and lexical context of pauses and hesitations in the discourse of Alzheimer patients and healthy elderly subjects. Clin Linguist Phon 25, 198-209.

[14] Hoffmann I, Nemeth D, Dye CD, Pákáski M, Irinyi T, Kálmán J (2010) Temporal parameters of spontaneous speech in Alzheimer's disease. Int J Speech Lang Pathol 12, 29-34.

[15] Singh S, Bucks RS, Cuerden JM (2001) Evaluation of an objective technique for analysing temporal variables in DAT spontaneous speech. Aphasiology 15, 571-583.

[16] Ullman MT (2004) Contributions of memory circuits to language: The declarative/procedural model. Cognition 92, $231-270$.
[17] Cannizzaro MS, Coelho CA (2013) Analysis of narrative discourse structure as an ecologically relevant measure of executive function in adults. J Psycholinguist Res 42, 527-549.

[18] Zellner B (1994) Pauses and the temporal structure of speech. In Fundamentals of Speech Synthesis and Speech Recognition, Keller E, ed. John Wiley, Chichester, pp. 41-62.

[19] Corley M, Stewart OW. Hesitation disfluencies in spontaneous speech: The meaning of um. Lang Linguist Compass 2, 589602 .

[20] Goldman Eisler F (1968) Psycholinguistics: Experiments in Spontaneous Speech, Academic Press, London.

[21] Merlo S, Mansur LL (2004) Descriptive discourse: Topic familiarity and disfluencies. J Commun Disord 37, 489-503.

[22] Bortfeld H, Leon SD, Bloom JE, Schober MF, Brennan SE (2001) Disfluency rates in conversation: Effects of age, relationship, topic, role, and gender. Lang Speech 44, 123-147.

[23] Ramanarayanan V, Bresch E, Byrd D, Goldstein L, Narayanan SS (2009) Analysis of pausing behavior in spontaneous speech using real-time magnetic resonance imaging of articulation. J Acoust Soc Am 126, EL160-EL165.

[24] Roark B, Mitchell M, Hosom J-P, Hollingshead K, Kaye J (2012) Spoken language derived measures for detecting mild cognitive impairment. Audio Speech Lang Process 7, 263-269.

[25] Ash S, Avants B, Grossman M (2011) Non-fluent speech in frontotemporal lobar degeneration. J Neurolinguistics 22, 370-383.

[26] Ash S, Xie S, Gross RG, Dreyfuss M, Boller A, Camp E, Morgan B, Shea JO, Grossman M (2013) The organization and anatomy of narrative comprehension and expression in Lewy body spectrum disorders. Neuropsychology 26, 368-384.

[27] Wilson SM, Henry ML, Besbris M, Ogar JM, Dronkers NF, Jarrold W, Miller BL, Gorno-Tempini ML (2010) Connected speech production in three variants of primary progressive aphasia. Brain 133, 2069-2088.

[28] Simons JS, Gilbert SJ, Owen AM, Fletcher PC, Burgess PW (2005) Distinct roles for lateral and medial anterior prefrontal cortex in contextual recollection. J Neurophysiol 94, 813-820.

[29] Volle E, Gonen-Yaacovi G, Costello ADL, Gilbert SJ, Burgess PW (2011) The role of rostral prefrontal cortex in prospective memory: A voxel-based lesion study. Neuropsychologia 49, 2185-2198.

[30] Roca M, Torralva T, Gleichgerrcht E, Woolgar A, Thompson R, Duncan J, Manes F (2011) The role of Area 10 (BA10) in human multitasking and in social cognition: A lesion study. Neuropsychologia 49, 3525-3531.

[31] Volle E, Gilbert SJ, Benoit RG, Burgess PW (2010) Specialization of the rostral prefrontal cortex for distinct analogy processes. Cereb Cortex 20, 2647-2659.

[32] Burgess PW, Dumontheil I, Gilbert SJ (2007) The gateway hypothesis of rostral prefrontal cortex (area 10) function. Trends Cogn Sci 11, 290-298.

[33] Barbeau EJ, Didic M, Felician O, Tramoni E, Guedj E, Ceccaldi M, Poncet M (2006) Pure progressive amnesia: An atypical amnestic syndrome? Cogn Neuropsychol 23, 1230-1247.

[34] Tramoni E, Aubert-Khalfa S, Guye M, Ranjeva JP, Felician O, Ceccaldi M (2009) Hypo-retrieval and hyper-suppression mechanisms in functional amnesia. Neuropsychologia 47, 611-624.

[35] Albert MS, DeKosky ST, Dickson D, Dubois B, Feldman HH, Fox NC, Gamst A, Holtzman DM, Jagust WJ, Petersen RC, Snyder PJ, Carrillo MC, Thies B, Phelps CH (2011) The diagnosis of mild cognitive impairment due to Alzheimer's disease: Recommendations from the National Institute on 
Aging-Alzheimer's Association workgroups on diagnostic guidelines for Alzheimer's disease. Alzheimers Dement 7, 270-279.

[36] Morris JC (1993) The Clinical Dementia Rating (CDR): Current version and scoring rules. Neurology 43, 2412-2414.

[37] Van der Linden M, Coyette F, Poitrenaud J, Kalafat M, Calicis F, Wyns C, Adam S (2004) L'épreuve de rappel libre/rappel indicè à 16 items (RL/RI-16). In L'évaluation des troubles de la mémoire: Présentation de quatre tests de mémoire épisodique avec leur étalonnage, Van der Linden M, ed. Solal, Marseille, France, pp. 25-47.

[38] Fazekas F, Barkhof F, Wahlund LO, Pantoni L, Erkinjuntti T, Scheltens P, Schmidt R (2002) CT and MRI rating of white matter lesions. Cerebrovasc Dis 13(suppl 2), 31-36.

[39] Wallon D, Rousseau S, Rovelet-Lecrux A, Quillard-Muraine M, Guyant-Maréchal L, Martinaud O, Pariente J, Puel M, Rollin-Sillaire A, Pasquier F, Le Ber I, Sarazin M, Croisile $\mathrm{B}$, Boutoleau-Bretonnière $\mathrm{C}$, Thomas-Antérion $\mathrm{C}$, Paquet $\mathrm{C}$, Moreaud O, Gabelle A, Sellal F, Sauvée M, Laquerrière A, Duyckaerts C, Delisle M-B, Streichenberger N, Lannes B, Frebourg T, Hannequin D, Campion D (2012) The French series of autosomal dominant early onset alzheimer's disease cases: Mutation spectrum and cerebrospinal fluid biomarkers. J Alzheimers Dis 30, 847-856.

[40] Wiltfang J, Esselmann H, Bibl M, Hüll M, Hampel H, Kessler H, Frölich L, Schröder J, Peters O, Jessen F, Luckhaus C, Perneczky R, Jahn H, Fiszer M, Maler JM, Zimmermann R, Bruckmoser R, Kornhuber J, Lewczuk P (2007) Amyloid $\beta$ peptide ratio 42/40 but not $A \beta 42$ correlates with phospho-Tau in patients with low- and high-CSF A $\beta 40$ load. J Neurochem 101, 1053-1059.

[41] Fleisher AS, Chen K, Liu X, Roontiva A, Thiyyagura P, Ayutyanont N, Joshi AD, Clark CM, Mintun MA, Pontecorvo MJ, Doraiswamy PM, Johnson KA, Skovronsky DM, Reiman EM (2011) Using positron emission tomography and florbetapir F18 to image cortical amyloid in patients with mild cognitive impairment or dementia due to Alzheimer disease. Arch Neurol 68, 1404-1411.

[42] Schreiber S, Landau SM, Fero A, Schreiber F, Jagust WJ, Alzheimer's Disease Neuroimaging Initiative (2015) Comparison of visual and quantitative florbetapir $\mathrm{F} 18$ positron emission tomography analysis in predicting mild cognitive impairment outcomes. JAMA Neurol 72, 1183-1190.

[43] Sarazin M, Berr C, De Rotrou J, Fabrigoule C, Pasquier F, Legrain S, Michel B, Puel M, Volteau M, Touchon J, Verny M, Dubois B (2007) Amnestic syndrome of the medial temporal type identifies prodromal AD: A longitudinal study. Neurology 69, 1859-1867.

[44] Rey A (1960) Test de copie d'une figure complexe [ReyOsterrieth Complex Figure Test], ECPA, Paris.
[45] Barbeau E, Didic M, Tramoni E, Felician O, Joubert S, Sontheimer A, Ceccaldi M, Poncet M (2004) Evaluation of visual recognition memory in MCI patients. Neurology 62, 13171322 .

[46] Wechsler D (1997) WAIS-III: Administration and Scoring Manual, Harcourt Brace \& Company.

[47] Lacot É, Barbeau EJ, Thomas-Anterion C, Basaglia-Pappas S, Pariente J, Puel M, Vautier S (2011) TOP 12: How to interpret the responses as a measure of collective memory? Rev Neuropsychol 3, 284-289.

[48] Reitan MR (1958) Validity of the Trail Making Test as an indicator of organic brain damage. Percept Mot Skills 8, 271276.

[49] Dubois B, Slachevsky A, Litvan I, Pillon B (2000) The FAB: A frontal assessment battery at bedside. Neurology 55, 16211626.

[50] Cardebat D, Doyon B, Puel M, Goulet P, Joanette Y. Evocation lexicale formelle et sémantique chez des sujets normaux. Performances et dynamiques de production en fonction du sexe, de l'âge et du niveau d'étude. Acta Neurol Belg 90, 207-217.

[51] Deloche G, Hannequin D (1997) Test de dénomination orale d'images: DO 80, Éd. du Centre de psychologieappliquée.

[52] Benton AL, Van Allen MW (1968) Impairment in facial recognition in patients with cerebral disease. Trans Am Neurol Assoc 93, 38-42.

[53] Spielberger CD, Gorsuch RL, Lushene RE (1970) Manual for the State-Trait Anxiety Inventory. Consulting Psychologists Press, Palo Alto, CA.

[54] Beck AT, Ward CH, Mendelson M, Mock J, Erbaugh J (1961) An inventory for measuring depression. Arch Gen Psychiatry 4, 561-571.

[55] Tramoni E, Felician O, Barbeau EJ, Guedj E, Guye M, Bartolomei F, Ceccaldi M (2011) Long-term consolidation of declarative memory: Insight from temporal lobe epilepsy. Brain 134, 816-831.

[56] Tzourio-Mazoyer N, Landeau B, Papathanassiou D, Crivello F, Etard O, Delcroix N, Mazoyer B, Joliot M (2002) Automated anatomical labeling of activations in SPM using a macroscopic anatomical parcellation of the MNI MRI singlesubject brain. Neuroimage 15, 273-289.

[57] Burgess P, Simons J, Dumontheil I, Gilbert S (2004) The gateway hypothesis of rostral PFC function. Trends Cogn Sci 11, 217-248.

[58] Basso Moro S, Cutini S, Ursini ML, Ferrari M, Quaresima V (2013) Prefrontal cortex activation during story encoding/retrieval: A multi-channel functional near-infrared spectroscopy study. Front Hum Neurosci 7, 925.

[59] Bliss LS, Mccabe A (2006) Comparison of discourse genres: Clinical implications. Curr Issues Commun Sci Disord 33, 126-137. 